\title{
Simple sensitivity analysis of a catchment scale water quality model at a range of spatio-temporal scales
}

\author{
$\underline{\text { B. Fentie }}^{\text {a }}$ and F. Bennett ${ }^{\text {a }}$ \\ ${ }^{a}$ Queensland Department of Science, Information Technology and Innovation \\ Email: banti.fentie@dsiti.qld.gov.au
}

\begin{abstract}
Fine sediment generated from catchments of the Great Barrier Reef (GBR) is considered to be one of the main pollutants of serious concern affecting the quality of water entering the reef. Estimation of the amount of sediment that is generated from these catchments and the proportion that enters the reef lagoon for a given combination of land use and land management is being carried out under the Paddock to Reef (P2R) Program using the eWater Source modelling platform and the Dynamic SedNet plugin. Currently, water quality monitoring data from selected sites, including end of system sites, are being used to manually calibrate and validate the water quality model. However, the manual calibration attempted so far has mainly been based on trial-and-error. The main objectives of the simple one-at-a-time (OAT) local sensitivity analysis reported here are to: (1) identify parameters that the model reacts most sensitively to in order to simplify and accelerate the calibration of the model; (2) examine if the results of the sensitivity analysis depend on the spatial and temporal scales of investigation; and (3) compare the results to a more computationally intensive global sensitivity analysis reported in an associated global sensitivity analysis paper to be presented in this conference (Bennett and Fentie, 2017).
\end{abstract}

The choice of parameters included in the sensitivity analysis was determined based on a preliminary investigation on a relatively small test sub-catchment in the Burnett catchment by the first author. The preliminary investigation showed that fine sediment load is most sensitive to changes in three parameters (i.e., streambank sediment bulk density $\left(\rho_{s}\right)$, hillslope sediment delivery ratio (HSDR) and gully sediment delivery ratio (GSDR)), which represent the three sources of sediment (streambank, hillslope and gully erosion, respectively) in the Source/Dynamic SedNet water quality model. The other three parameters included in the analysis - floodplain deposition settling velocity $\left(V_{p}\right)$, channel average terminal fall velocity for fine sediment remobilization $\left(\omega_{\text {dep }}\right)$, and channel average terminal fall velocity for fine sediment deposition $\left(\omega_{m o b}\right)-$ represent the effect of settling velocity of particles on sediment deposition on the floodplain and in the stream, and channel remobilization, respectively.

In order to explore the effect of catchment size and other characteristics on the sensitivity analysis, three locations with differing catchment area were chosen in this study. The location with the smallest catchment area drains the upper parts of the Burnett catchment while the location with the largest catchment area represents the Burnett catchment end of system $(\mathrm{EoS})$. The third location is at the outlet of the Mary catchment.

Temporal variability in results of the sensitivity analysis was investigated by conducting the analysis at an annual time step summarised from the daily time-step model outputs of the 28 years modelling period of the Great Barrier Reef catchment modelling for Report Card 2016.

Results show that: (1) the modelled fine sediment loads were relatively highly sensitive to changes in streambank sediment bulk density $\left(\rho_{s}\right)$, hillslope sediment delivery ratio (HSDR) and gully sediment delivery ratio (GSDR), but were only marginally sensitive to changes in the other three parameters; (2) the sensitivity of fine sediment load to changes in parameters varied across the three locations; and (3) the sensitivity of fine sediment load to changes in parameters varied annually. Sensitivities from this study have similar rankings of parameters to those from Bennet and Fentie (2017). Both approaches determined that modelled fine sediment load is relatively insensitive to changes in particle settling velocity parameters for both stream deposition and channel remobilization. Based on these findings it is concluded that (1) the simple one-at-a-time sensitivity analysis conducted in this study is adequate in determining the sensitivity of modelled sediment to changes in model parameters; and (2) since results of the local sensitivity analysis vary spatially from catchment to catchment and temporally from year to year, the analysis needs to be carried out for each specific catchment and period of interest.

Keywords: $\quad$ Sensitivity analysis, water quality model, Source model, Dynamic SedNet, Great Barrier Reef 


\section{INTRODUCTION}

Fine sediment generated from catchments of the Great Barrier Reef is considered to be one of the pollutants of concern affecting the quality of water entering the reef. Estimation of the amount of sediment that is generated from the catchments and the proportion that enters the reef lagoon for a particular combination of land use and land management combination is being carried out by the Paddock to Reef (P2R) Program under the Reef Water Quality Protection Plan (Department of the Premier and Cabinet, 2009) using the eWater Source modelling platform (Delgado, 2012) and the Dynamic SedNet plugin (Ellis and Searle, 2014). Source provides a flexible structure that allows selection of model complexity appropriate to the problem at hand and within any constraints imposed by availability of data and knowledge (Ellis and Searle, 2014). Application of the Dynamic SedNet water quality plugin demonstrates the flexibility of Source. The main function of this plugin is to model the generation of sediment from different sources (hillslope, gully and streambanks), its supply to and transport through the stream network, and finally export to a receiving environment, in this case to the GBR lagoon.

Water quality monitoring data at selected sites, including end of system, are being used to manually calibrate and validate the water quality model. However, while targeting dominant sources of fine sediment, the manual calibration attempted so far has mainly been based on trial and error. Sensitivity analysis (SA) is a valuable tool for developing, modifying, calibrating, and testing a model (Sieber, 2005). It is a useful tool to (i) identify parameters the model reacts most sensitively to and thus simplify and accelerate the calibration of the model or enable a more focused planning of future research and field measurement, (ii) show whether the model's response to representative variations of parameter values and boundary conditions is realistic, (iii) prove the model concept to be sufficiently sensitive to represent the natural system's behaviour, and (iv) reduce a model to its essential structures. Generally, there are two types of sensitivity analysis, local and global. Local sensitivity analysis is performed by changing values one at a time, and global (Rosero et al., 2010), by allowing all parameter values to change simultaneously.

The main objectives of the simple one-at-a-time (OAT) local sensitivity analysis (Hamby, 1994) reported here are (1) to identify parameters that the model is the most sensitive to, (2) to explore if the results of the sensitivity analysis depend on the spatial and temporal scales of investigation, and (3) to compare the results from a more computationally intensive global sensitivity analysis (Bennett and Fentie, 2017). The sensitivity analysis conducted in this study is similar to that carried out by Fentie et al. (2005). However the study by Fentie et al. (2005) was based on the long-term annual average water quality model called SedNet (Wilkinson, 2004) and included hydrology model parameters.

The choice of parameters to be included in the sensitivity analysis was based on preliminary investigation using a relatively small test sub-catchment in the Burnett catchment by the first author. This preliminary investigation showed that modelled fine sediment load is most sensitive to changes in streambank sediment bulk density $\left(\rho_{s}\right)$, hillslope sediment delivery ratio (HSDR) and gully sediment delivery ratio (GSDR), representing the three primary sources of sediment (streambank, hillslope and gully erosion, respectively) in the Source/Dynamic SedNet water quality model. The other three parameters (floodplain deposition settling velocity $\left(V_{p}\right)$, channel average terminal fall velocity for fine sediment remobilization $\left(\omega_{d e p}\right)$, and channel average terminal fall velocity for fine sediment deposition $\left(\omega_{m o b}\right)$ ) represent the effect of settling velocity of particles on sediment deposition on the floodplain and in the stream, and channel remobilization, respectively.

In order to explore the effect of catchment size and other characteristics on the sensitivity analysis results, three locations with different sizes of catchment were chosen in this study. The location with the smallest catchment area $\left(7093 \mathrm{~km}^{2}\right)$ drains the upper parts of the Burnett catchment while the location with the largest catchment area $\left(33,020 \mathrm{~km}^{2}\right)$ represents the Burnett catchment end of system (EoS). The third location with $9466 \mathrm{~km}^{2}$ catchment area is at the outlet of the Mary catchment. The choice of these locations in the Burnett and Mary catchments includes the largest two catchments in the Burnett Mary region, which between them contribute about 89 percent of the modelled fine sediment load exported to the coast from this region (McCloskey et al., 2017).

Temporal variability of parameter sensitivity is investigated in this paper through analysis of 28 years of annualised model results summarised from daily time step model outputs. 
Fentie and Bennett, Simple sensitivity analysis of a catchment scale water quality model

\section{MATERIALS AND METHODS}

\subsection{The model and choice of parameters}

Table 1 shows a description, possible range and values of each model parameter included in the sensitivity

Table 1. Model parameters and range of values used in the sensitivity analysis

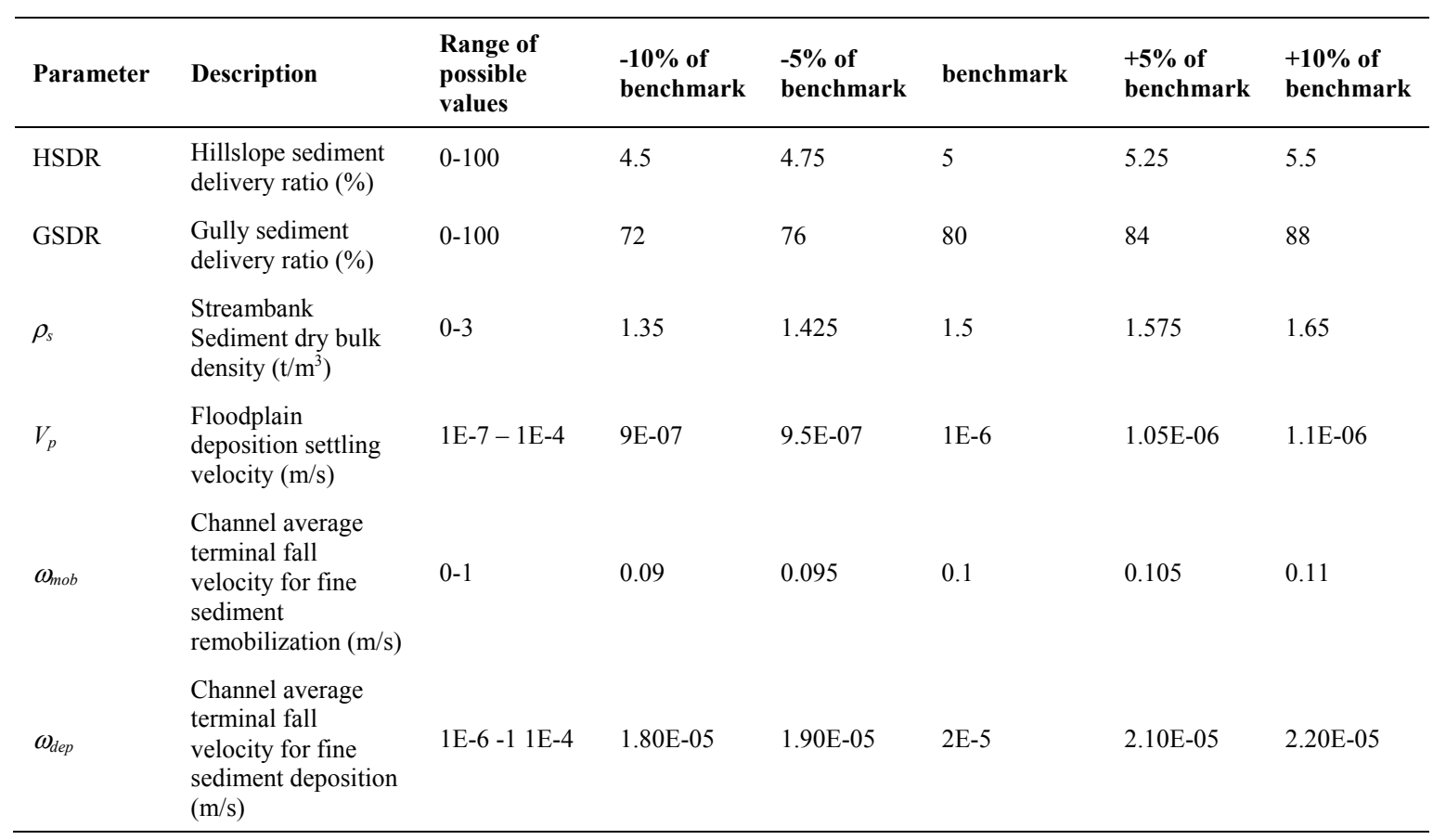

analysis. Values of each parameter currently in the model (benchmark) and values with $-10 \%,-5 \%,+5 \%$, and $+10 \%$ changes from the benchmark are also given. For a detailed description of the parameters, the reader is referred to Ellis and Searle (2014). Despite the fact that streambank sediment dry bulk density $\left(\rho_{s}\right)$ is not typically calibrated in model construction, it is included in the sensitivity analysis to highlight the importance of accurate values of this parameter as preliminary investigation indicated that the model was very sensitive to changes in this input data.

\subsection{The study area}

The Burnett Mary Natural Resources Management (NRM) Planning Region includes coastal catchments south of the Fitzroy Catchment to the Noosa River, including the RAMSAR listed Great Sandy Straits and the Fraser Island World Heritage Area. The two largest catchments are the Burnett River $\left(33,038 \mathrm{~km}^{2}\right)$ and the Mary River $\left(9466 \mathrm{~km}^{2}\right)$, which discharge into Hervey Bay at the southern tip of the Great Barrier Reef Marine Park.

The region experiences a typically humid subtropical climate with distinct wet and dry seasons. Rainfall in the NRM region varies from less than $1200 \mathrm{~mm}$ /year in the semi-arid Burnett River Headwaters to 1200 - 1800 $\mathrm{mm} /$ year in the humid coastal strip and Mary River. Land use patterns strongly follow variations in soils and rainfall across the Burnett Mary NRM region. At the regional scale, land uses are structured as a gradient between nature conservation (more dominantly in the Mary) to grazing (more dominantly in the Burnett). Irrigated cropping and dry-land cropping are also prevalent in the Burnett; in contrast to fruit and vegetable produce, rural residential, pine forestry, and dairy in the Mary.

This study is based on modelled fine sediment loads at three different locations in the two major basins (Burnett and Mary) in the Burnett Mary regional model for the Reef Water Quality Protection Plan (McCloskey, 2017). Figure 1 shows the location of the three sites where modelled fine sediment loads have been summarised for 
the sensitivity analysis in this study. Catchment areas of the three locations are $7093 \mathrm{~km}^{2}$ for 136106A, 33,020 $\mathrm{km}^{2}$ for $136014 \mathrm{~A}$ and $9466 \mathrm{~km}^{2}$ for the Mary outlet.

\subsection{The sensitivity index}

When an explicit algebraic equation describes the relationship between the independent variables and the dependent variable, the sensitivity index (SI) for a particular independent variable can be calculated from the partial derivative of the dependent variable with respect to the independent variable (Hamby, 1994) as:

$$
S I=\frac{\partial Y}{\partial X}\left(\frac{X}{Y}\right)
$$

where $\mathrm{X}$ is the benchmark parameter value and $\mathrm{Y}$ is the corresponding model output. The ratio $\mathrm{X} / \mathrm{Y}$ is introduced to normalize the sensitivity index by removing the effects of units. This formulation is based on the assumptions that the higher ordered partial derivatives are negligible and there is no correlation between input parameters (Atherton, 1975; Gardner, 1981).

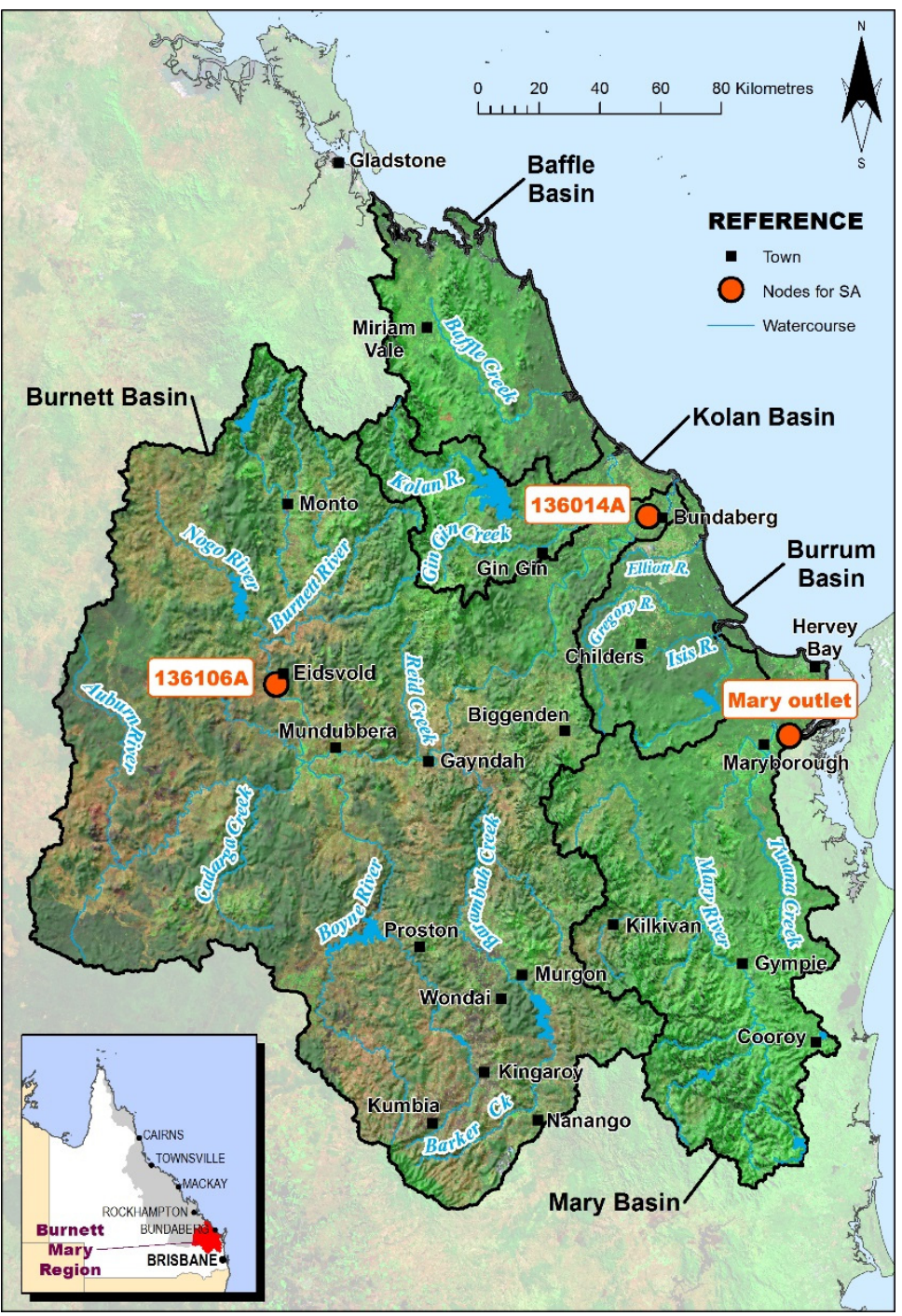

Figure 1. Location of the three sites at which the sensitivity analysis has been carried out

Neglecting non-linearity, the partial derivative for the local one-at-a-time sensitivity analysis method adopted in this study can be approximated by a finite difference (Hamby, 1994) as:

$$
S I_{i j}=\frac{\% \Delta Y_{i j}}{\% \Delta X_{i j}}=\frac{\left(Y_{i j}-Y_{i b}\right) / Y_{i b}}{\left(X_{i j}-X_{i b}\right) / X_{i b}}
$$

where $S I_{i j}$ is a dimensionless sensitivity index for the $\mathrm{j}^{\text {th }}$ value of parameter $\mathrm{i} ; \% \Delta Y_{i j}$ and $\% \Delta X_{i j}$ are percentage changes in output $\left(\mathrm{Y}_{i j}\right)$ and parameter $\left(\mathrm{X}_{i j}\right)$ from their benchmark values, respectively; and $\mathrm{Y}_{i b}$ and $\mathrm{X}_{i b}$ are, respectively, the benchmark output and parameter values of the parameter i. The Source model with the Dynamic SedNet plugin produces various outputs for each model element. The output of interest in this study is fine sediment load at the three locations.

In order to generate the data necessary to complete the sensitivity analysis, a total of 25 model runs were carried out (i.e., 4 runs per parameter $\times 6$ parameters +1 run for the bench mark).

The interpretation of the sensitivity index determined from Equation (1) is as follows:

- a value of zero indicates that the model is not sensitive to changes in the parameter

- a negative value indicates that the model output decreases as the parameter increases

- a positive value indicates that the model output increases as the parameter increases

- the model is the most sensitive to parameters with high absolute value sensitivity indices. 


\section{RESULTS}

Figure 2 shows the annual variability of sensitivity indices of parameters on the left $y$ axis and flow (GL) on the right y-axis at 136106A (top), 136014A (middle) and Mary outlet (bottom). At all three locations, there is very high temporal variability in sensitivity indices of all parameters. Although not shown in Figure 2 due to the maximum scale being kept at 1.2 for readability and ease of comparison, at $136014 \mathrm{~A}$, fine sediment load was particularly very sensitive to:

- parameter $\rho_{s}$ in 1993/94 and 1994/95 with sensitivity indices of 4.5 and 5.4, respectively

- $\quad$ parameter $\omega_{\text {mob }}$ in 1992/93, 1993/94 and $1994 / 95$ with sensitivity indices of 4.8 , $6.3,5.3$, respectively.

Table 2 shows average sensitivity indices of all six parameters included in the sensitivity analysis at the three locations. It appears that, of the six parameters, fine sediment load is relatively more sensitive to $\rho_{s}$, HSDR and GSDR than the other three parameters. Fine sediment load increases with increasing values of these three parameters as depicted by the corresponding positive sensitivity index values. The sensitivity of the model to changes in HSDR is the highest at the Mary outlet and the lowest at 136014A. As the result of the higher prevalence of gullies in the catchment of 136106A, the effect of changes in GSDR on fine sediment load is highest at this location while it is the lowest at the Mary outlet with a catchment where the incidence of gullies is relatively low. Fine sediment load is equally sensitive to changes in $\rho_{s}$ at the two locations with the largest catchment areas (136014A and Mary outlet) whilst being relatively less sensitive at the location with the smallest catchment area (136106A). This is to be expected as stream power, which is the driving force for streambank erosion in the relevant algorithm, usually increases with catchment area. Table 2 shows that the other three parameters have relatively low average sensitivity index values. Therefore, effort in obtaining realistic parameters should be directed towards the three parameters the model is the most sensitive to rather than those to which the output of interest is not significantly sensitive to.

Table 2. Average sensitivity indices of the six parameters at the three locations

\begin{tabular}{|l|r|r|r|}
\hline Location & 136106A & 136014A & Mary outlet \\
\hline HSDR & 0.11 & 0.09 & 0.23 \\
\hline GSDR & 0.47 & 0.27 & 0.03 \\
\hline$\rho_{\mathrm{s}}$ & 0.38 & 0.66 & 0.66 \\
\hline $\mathrm{V}_{\mathrm{p}}$ & -0.08 & -0.07 & -0.01 \\
\hline$\omega_{\mathrm{dep}}$ & 0.00 & -0.08 & 0.00 \\
\hline$\omega_{\mathrm{mob}}$ & -0.03 & 0.08 & -0.02 \\
\hline
\end{tabular}




\section{DISCUSSION AND CONCLUSIONS}

When assessed against the four roles of sensitivity analysis (refer to the introduction section), the results indicate that: (i) model calibration (and planning of future research and fieldwork) can be accelerated and focused by targeting only those parameters which the model is the most sensitive to; (ii) the model's response to representative variations of parameter values and boundary conditions is realistic; (iii) the model concept is sufficiently sensitive to represent the natural system's behaviour in that fine sediment export has been determined to be sensitive to parameters related to all three sources of sediment (i.e., hillslope erosion, gully erosion, and streambank erosion); and (iv) the model could be reduced to its essential structures by fixing parameters to which it is not sensitive which has implications for model calibration. In brief, the results of this simple local sensitivity analysis have been useful in identifying parameters to which the Dynamic SedNet model output of interest (fine sediment export) is the most sensitive and those that have negligible or no influence at all. This information is vital in focusing our attention on those parameters to which the model is the most sensitive. Out of the six model parameters included in the sensitivity analysis, only changes in three have been found to significantly influence fine sediment export at the three locations.

Although it has been demonstrated that the more complex global sensitivity analysis (Bennett and Fentie, 2017) and this simple OAT local sensitivity analysis conducted in this study resulted in similar ranking of sensitivity indices, it should be noted that local one-at-a-time sensitivity analysis: (a) does not include parameter interactions; (b) does not include model output uncertainty due to uncertainty in spatial input datasets; and (c) only investigated four changes in each parameter value out of thousands of possibilities. Therefore, where it is computationally feasible, a more robust global sensitivity analysis is recommended.

The spatial issues highlighted here are consistent with the findings of Newham (2003) who showed that the model is more sensitive at larger spatial scales than at smaller spatial scales.

Despite the limitations outlined above, the local sensitivity analysis adopted in this study has been valuable in quickly identifying parameters the model is most sensitive to, and therefore, directing research efforts towards obtaining realistic values for these parameters.

Results show that: (1) the sensitivity of modelled fine sediment loads were relatively high to streambank sediment bulk density $\left(\rho_{s}\right)$, hillslope sediment delivery ratio (HSDR) and gully sediment delivery ratio (GSDR), with very minimal sensitivity to the other three parameters; (2) the sensitivity of fine sediment load to changes in parameters varied across the three locations; and (3) the sensitivity of fine sediment load to changes in parameters varied annually. It has also shown that comparison of current results with corresponding findings from the more computationally intensive global sensitivity analysis (Bennett and Fentie, 2017) indicate that both methods have similar parameter rankings. Moreover, secondary indices showing the level of interactions between parameters available from Bennett and Fentie (2017) were zero or close to zero, indicating the adequacy of the simple sensitivity analysis reported in this paper and for this particular model setup which required only 25 model runs compared to hundreds or even thousands of model runs that would be required for a comparable global sensitivity analysis, each model run of the Burnett Mary regional model taking about 30 minutes. Furthermore, both approaches determined that modelled fine sediment load is relatively insensitive to changes in particle settling velocity parameters for both stream deposition and channel remobilization. Based on these findings it is concluded that: (1) the simple one-at-a-time sensitivity conducted in this study is adequate in determining the sensitivity of modelled sediment to changes in model parameters; and (2) as results of the local sensitivity analysis of the fine sediment generation, transport and export model vary spatially from catchment to catchment and temporally on annual basis, the analysis needs to be carried out for each specific catchment and period of interest.

In general, sensitivity of the model to a parameter appears to depend on the relative contribution of the source of fine sediment (hillslope, gully, and streambank) in which the parameter is involved in to export rather than spatial scale. As highlighted by Fu et al. (2017), this may be due to the possibility of local responses having little overall impact on the outputs at the end of the system as the result of fine sediment load reductions associated with reservoir trapping, floodplain deposition and other losses en route.

The exploration of annual variability of sensitivity indices reveals some interesting relationships: there is a general increasing trend in the sensitivity of fine sediment load to changes in $\rho_{s}$ as flow increases whilst there appears to be a decreasing trend to changes in HSDR and GSDR as flow increases. It is also noted that whilst the average sensitivity indices for the three sediment settling velocity parameters (i.e., $V_{p}, \omega_{\text {dep }}$, and $\omega_{\text {mob}}$ ) are very small at all three locations, their variability through time is quite high, as shown in Figure 2. Seeking for explanations for these annual variabilities in sensitivity indices is a subject for further investigation. 
Fentie and Bennett, Simple sensitivity analysis of a catchment scale water quality model

\section{REFERENCES}

Atherton, R.W., Schainker, R.B., and Ducot, E.R. (1975). On the Statistical Sensitivity Analysis of Models for Chemical Kinetics, AIChE., (21), pp. 441-448.

Bennett, F. R., and Fentie, B. (2017). Sensitivity analysis of constituent generation parameters of an integrated hydrological and water quality model using a GMDH polynomial neural network. MODSIM 2017

Delgado, P., Kelley, P., Murray, N., and Satheesh, N. A. (2012). Source: User Guide.

Department of the Premier and Cabinet, T. S. o. Q. (2009). Reef Water Quality Protection Plan, 2009, For the Great Barrier Reef World Heritage Area and adjacent catchments: The State of Queensland and the Commonwealth of Australia. www.reefplan.qld.gov.auReport).

Ellis, R. J., and Searle, R.D. (2014). Dynamic SedNet Component Model Reference Guide. Concepts and algorithms used in Source Catchments customisation plugin for Great Barrier Reef catchment modelling., Bundaberg, Queensland: Queensland Department of Science, Information Technology, Innovation and the ArtsReport).

Fentie, B., Marsh, N., and Steven, A. (2005). Sensitivity Analysis of a Catchment Scale Sediment Generation and Transport Model. MODSIM 2005 International Congress on Modelling and Simulation., 2005: Modelling and Simulation Society of Australia and New Zealand, 1140-1146.

Fu, B., Ellis, R., Croke, B, Rahman, J., Waters, D. and Jakeman, A. (2017). Sensitivity analysis of the GBR Source catchment models. MODSIM 2017

Gardner, R. H., O'Neill, R.V., Mankin, J.B. and Carney, J.H. (1981). A Comparison of Sensitivity Analysis and Error Analysis Based on a Stream Ecosystem Model, Ecol. Modelling, (12), pp. 173-190.

Hamby, D. M. (1994). A review of techniques for parameter sensitivity analysis of environmental models, Environmental Monitoring and Assessment, (32), pp. 135-154.

McCloskey, G. L., Waters, D., Baheerathan, R., Darr, S., Dougall, C., Ellis, R., Fentie, B., and Hateley, L.R. (2017). Modelling pollutant load changes due to improved management practices in the Great Barrier Reef catchments: updated methodology and results. Technical Report for Reef Report Card 2014: Queensland Department of Natural Resources and Mines.

Rosero, E., Yang, Z., Wagener, T., Lindsey E. Gulden, L. E, Soni Yatheendradas, S., and Niu, G. Y. (2010). Quantifying parameter sensitivity, interaction, and transferability in hydrologically enhanced versions of the Noah land surface model over transition zones during the warm season, Journal of Geogrphical Research, 115, pp. 1-21.

Newham, L. T. H., Norton, J.P., Prosser, I.P., Croke, B.F.W. and Jakeman, A.J. (2003). Sensitivity analysis for assessing the behaviour of a landscape-based sediment source and transport model., Environmental Modelling and Software 18, pp. 741-751.

Sieber, A., and Uhlenbrook, S. (2005). Sensitivity analyses of a distributed catchment model to verify the model structure., Journal of Hydrology, 310, pp. 216-235.

Wilkinson, S., Henderson, A., and Chen, Y. (2004). SedNet User Guide. Client Report for the Cooperative Research Centre for Catchment Hydrology, Canberra: CSIRO Land and WaterReport). 